\title{
Foreign Bodies of Dental Origin in the Appendix
}

\author{
Wg Cdr TK Mellor \\ BDS, FDSRCPS, MBBCh, RAF \\ Senior House Officer \\ Lt Col SG Mellor \\ MBBS, FRCS(Eng), RAMC \\ Consultant Surgeon
}

Department of Surgery, Princess Alexandra's RAF Hospital, Wroughton, Swindon, Wilts SN4 OQJ

\section{Case Reps延

SUMMARY: Foreign bodies found in the appendix have been reported many times. To date 254 occurrences have been documented. However, only 4 previously reported episodes involve teeth, dental restoration or dent력

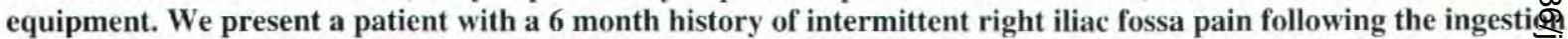
of a gold inlay restoration, which was found at operation to be in the distal appendix.

Previous reports suggest that symptoms from foreign bodies in the appendix occur in $73 \%$ of cases, and in $93 \frac{\mathrm{m}}{\mathrm{S}}$ when the object is sharp. Therefore, appendicectomy is recommended when a foreign body is detected in the appendix, and particularly if it has sharp edges.

\section{Introduction}

Foreign bodies of many types have been found in the appendix (1), although most traverse the gut without incident. A review of the literature has located two cases of teeth found in the appendix $(2,3)$, one dislodged crown (4) and one endodontic reamer (5). We present a further case of ingestion of a gold inlay restoration resulting in chronic appendicitis.

\section{Case Report}

A 48 year old male presented with intermittent mild abdominal pain localised to the right iliac fossa. He had previously undergone restoration of 24 (upper left first premolar) with a distal occlusal gold inlay in 1981. Over the subsequent 11 years this inlay had become dislodged on several occasions and had required recementing. However in 1992, six months before presentation, he swallowed the inlay. This was not investigated further until the inlay was noted as a incidental finding on a lumbar spine X-ray for investigation of back pain. On direct questioning he complained of intermittent mild right iliac fossa. On examination he was mildly tender in the right iliac fossa but had a normal rectal examination. White blood cells were $10.18 \times 109 / 1$ with a normal differential. An abdominal X-ray (Fig 1) shows the gold inlay in the right iliac fossa.

At operation the gold inlay was found at the distal tip of the appendix with historical evidence of focal inflammation and granulation tissue with a large number of polymorphs. He made an uneventful post operative recovery.

\section{Discussion}

The first reported appendicectomy was in 1735 by Amyand, a London surgeon (6), who removed an

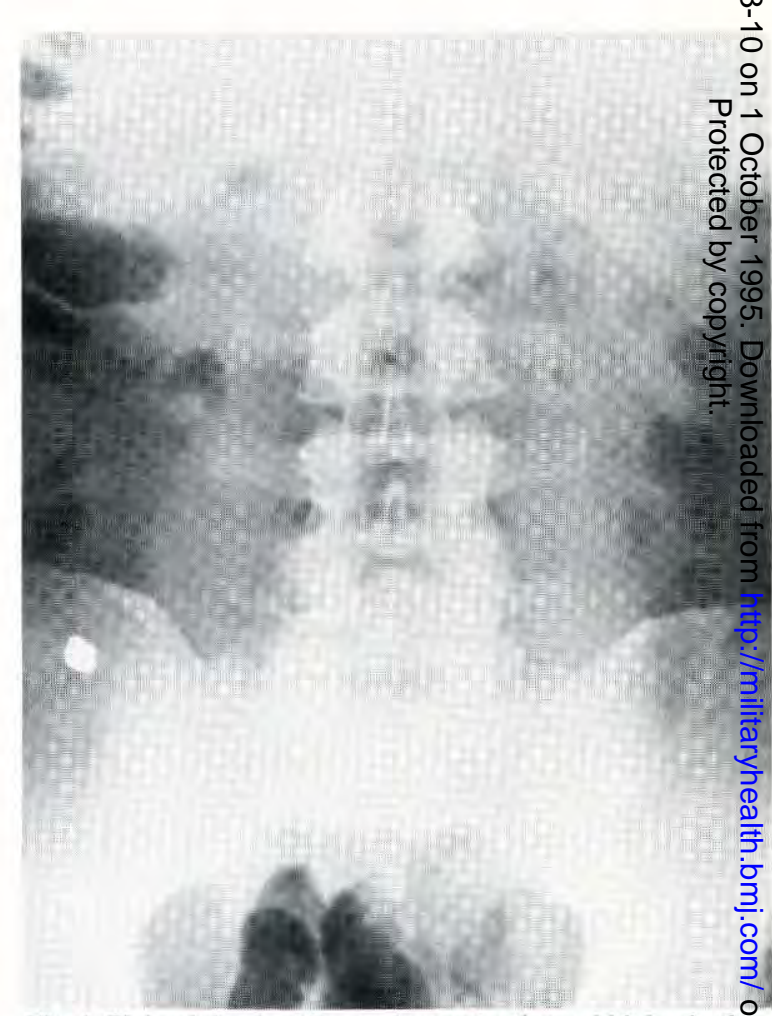

Fig 1. Plain abdominal X-ray demonstrating gold inlay in the right iliac fossa.

appendix perforated by a pin from an eleven year o셩 Many cases of foreign bodies in the appendix we reported by Balch \& Silver (1) who collected 225 ca: previously reported in the literature by 1971 . Since the another 29 have been added (4,5,7-24). Collins (25), i⿺辶a 
study of foreign bodies, found in over 71,000 appendices, over a 40 year period, an incidence of $3 \%$. Balch \& Silver (1) however only found an incidence of $0.0005 \%$ in over 13,000 appendices. The disparity in incidence probably reflects the care with which appendiceal concentrations (appendicoliths) are sought for in a nidus (8). The most common foreign bodies reported, in descending order, are pins, shot, bone and seed. In addition a multitude of miscellaneous items have been found including, stones, shell, solder, glass, enamel, coal, wood, nails, hair. mercury batteries and the mercury end of a thermometer.

Very few dental objects have been found in the appendix. Upton (2) first reported the ingestion of a tooth followed 6 weeks later by acute appendicitis in 1924 . Christeller \& Mayer (3) found a perforated appendix caused by the root of a swallowed tooth. These are the only two reported cases involving teeth. A crown was found occluding the lumen in acute appendicitis 24 hours after ingestion (4). The case we report here is only the second dental restoration to lodge in the appendix reported in the literature. The recognised hazard of injestion of an endodontic reamer, is well documented and the use of rubber dam is recommended to avoid ingestion. Reamers have been retrieved from the bronchial tree, stomach, duodenum and the colon (5). There is one reported case of endodontic reamer found in the appendix (5).

Heavy objects that enter the caecum will tend to gravitate towards the lowermost portion, the area from where the appendix generally arises. If the appendiceal orifice is patent the object may enter, but normally the appendix can empty its contents by peristaltic activity. However if the object is heavy the peristalsis of the appendix may be insufficient to expel it. Formation of a concretion around the foreign object may also help to prevent its escape. Sharp and pointed objects may injure the mucosa and initiate an inflammatory response (1). Pins will generally orientate themselves blunt end first in the gut. If the sharp end impinges on the alimentary mucosa the blunt end is deflected distally. This will help the passage through the bowel but if a pin enters the appendix, the peristaltic movement of the appendix will tend to impact the sharp end into the appendix wall, causing an inflammatory response. It follows therefore that pointed objects are more likely to cause symptoms. Balch \& Silver (1) report an incidence of $93 \%$ pointed objects causing symptoms and overall $71 \%$ of patients with foreign bodies in their appendices were symptomatic.

In conclusion, appendicetomy is recommended whenever a foreign body is detected in the appendix, and particularly if it has sharp edges.

\section{REFERENCES}

1. BALCH CM, SILVerD. Foreign bodies in the appendix. Arch Surg 1971; 102: 14-20.

2. Upton CL. An unusual case of apprencitis. Boston Med Surg J 1924; 190: 634.
3. Christeller E, Mayer E. Wurmfortsatzentzundung In; Henke and Lubarsch's handbuch der Speziellen Pathologischen Anatomie und Histologie. 1929; 4 part 3: 556 .

4. Meyer CA, Rosi PA. Acute appendicitis caused by foreign bodies. Am J Surg 1932; 17: 66-68.

5. Thomsen LC, Appleton SS, Engstrom HIM. Appendicitis induced by an endodontic file. Gen Dent 1989; 37: 50-51.

6. AMYAND C. Of an inguinal rupture with a pin in the appendix caeci encrusted with stone: some observations on wounds in the guts. Philos Trans 1736; 39: 329.

7. Geddes TG, Fernandez B, Duffy BL. Foreign body in the appendix. Br Med J 1972; 2(805): 114.

8. Kassner EG, Mutchier RW et al. Uncomplicated foreign bodies of the appendix in children: radiologic observations. J Pediatr Surg 1974; 9: 207-11.

9. Gupta B, Sircar M. Appendicular dyspepsia due to stones (foreign body), J Indian Med Assoc 1974; 62: 168-169.

10. DUCKLER L. Foreign body producing appendicitis. Clin Pediatr Phila 1976; 15: 383.

11. STENSTROM JD, RaINE R J. The nonmigrating pin (let- 을 ter). Can Med Assoc J 1978; 118: 1200.

12. ZaGroen AJ, Sillverman D, el al. Intra-appendice foreign body: report of a case and review of the litere ture. J Am Osteopath Assoc 1981; 80: 622-624.

13. Kekomaki M, Pekkala E. Right hydronephrosis f\& lowing ingestion of a foreign body. J Urol 1981; 128 \& 795.

14. Meyer J, Abuabara S, et al. A bullet in the appendie J Trauma 1982; 22: 424-425.

15. ATTARD GJ. Trichbezoar - an unusual cause of acute appendicitis. JR Army Med Corps 1983; 129: 117.

16. SMITH DA. Gangrenous appendicitis associated with an appendiceal trichobezoar (letter). Lancet 1983; vol 1: 1390.

17. Sherlock DJ, Ambrose NS. An unusual case of appendicitis. JR Coll Surg Edinh 1985; 30: 318.

18. REDDY ER. Retained lead shot in the appendix. J Can Assoc Radiol 1985; 36: 47-48.

19. Meltzer SJ, Goldberg MD, et al. Appendiceal obstruction by a toothpick removed at colonoscopy. Am J Gastroenerol 1986; 81: 1107-1108.

20. StRetCh J, Bilous M, CASS D. Tricholuminal appendicitis: an unusual cause. Aust NZ Surg 1986; 56: $731-732$.

21. CONFORTI FP, SMEgo DR, KAZARIAN KK. Halloween appendicitis: pin perforation of the appendix. Conn을 Med 1987; 51: 507.

22. Horby-Petersen J, Kristiansen, T, Jelnes R. Acute appendicitis caused by metallic foreign body (bullet). N Case report. Acta Chir Scand 1987; 153: 697-698.

23. Price J, Dewar GA, Metreweli C. Airgun pellet appendicitis. Australas Radiol 1988; 32: 368-370. 
24. Mizrahi S, Eyal I, Shtamler B. Foreign body removal through an appendicostomy. Dis Colon Rectum 1990; 33: 902.
25. Collins DC. Seventy-one thousand human append specimens. Amer J Proctol 1963; 14: 365-381. 